\title{
APATIA MULTIMODAL IATROGÊNICA
}

\author{
RICARDO DE OLIVEIRA-SOUZA*, WAGNER MARTIGNONI DE FIGUEIREDO**
}

RESUMO - O presente trabalho documenta um efeito peculiar dos antidepressivos em 5 pacientes - a apatia -, definida pela incapacidade de experimentar emoçōes. O reconhecimento da apatia no curso de tratamento antidepressivo deve levantar a possibilidade de iatrogenia e suspensão do antidepressivo em uso. Frizemos que a apatia deve ser diferenciada da abulia e da avolição, com as quais é comumente confundida. Documentamos que a indiferença emocional pode se confinar a um dominio sensorial ("apatia unimodal") ou, como em nossos casos, a mais de uma modalidade ("apatia multimodal"). Circuitos anterobasais, centrados na amigdala e no pólo temporal, são fortes candidatos para integrar a experiência emocional às imagens mentais e percepçð̃es multimodais do ambiente, uma vez que para eles convergem os principais sistemas de projeção do prosencéfalo, ao mesmo tempo em que se situam em pontos estratégicos para modular o córtex pré-frontal e parieto-têmporooccipital. $O$ fato de que a apatia foi produzida por classes quimicamente distintas, como ISRSs (inibidores seletivos de recaptação da serotonina), IMAOs (inibidores reversíveis da monoamino oxidase) e tricíclicos, indica que a fisiopatologia em jogo se deve a alguma açăo compartilhada por essas drogas no plano subneuronal. A intervenção em circuitos serotoninérgicos cerebrais parece o mecanismo mais adequado para explicar tal efeito.

PALAVRAS-CHAVE: antidepressivos, apatia, sistema limbico, abulia, avoliç̃̃o.

Multimodal apathy: a unique effect of antidepressant therapy at the neurological-psychiatric interface

ABSTRACT - The present paper reports on five patients who developed apathy as a peculiar side effect of antidepressants. Their behavioral and psychopathological changes were primarily due to the near-absence of emotional experience, a key characteristic that distinguishes apathy from avolition and abulia. The emergence of apathy in the course of an antidepressant treatment should raise the suspicion of an adverse effect of the drug and lead to its prompt withdrawal. A sample of the relevant clinical evidence favoring the distinction of apathy confined to a single sensory domain ("unimodal apathy") from apathy confined to more than one sensory realm ("multimodal apathy") is reviewed. From a pathophysiological standpoint, it would appear that neural nets centered in the amygdala-temporo polar cortex are critical for the integration of sensory perceptions and mental imagery with appropriate emotional tone and quality as well as with their accompanying somatic markers, as they receive afferents from the major projection systems of the prosencephalon and lie in nodes strategic to modify the ongoing activity of multiple parallel brain systems. The fact that one common symptom can be produced by such a heterogeneous family of substances points to a shared neurochemical mechanism of action. At present, discrete cerebral serotoninergic circuits would appear to be suitable candidates for such a role. Cases as these may be critical for the understanding of the cerebral organization of emotions in man, lending support to the notion that distinct neurochemical systems mediate discrete psychopathological symptoms.

KEY WORDS: antidepressants, apathy, limbic system, abulia, avolition.

A "apatia" - habitualmente descrita pela "indiferença do humor e aplanamento das reaçōes emocionais"19 — ingressou na literatura neurocomportamental sob a designação de "placidez" como

* Professor Assistente, Serviço de Clinica Médica C (Prof. Omar da Rosa Santos) do Hospital Universitário Gaffrée e Guinle (HUGG,UNI-RIO), Rio de Janeiro; **Professor Adjunto, Serviço de Clínica Médica C (Prof. Omar da Rosa Santos) do HUGG,UNI-RIO, Rio de Janeiro. Aceite: 11-janeiro-1996.

Dr. Ricardo de Oliveira Souza - Rua General Belford 226 - 20961-000 Rio de Janeiro RJ - Brasil. 
uma das manifestações axiais da síndrome de Klüver-Bucy (sKB). Em seres humanos ${ }^{13} \mathrm{e}$ em animais de experimentação ${ }^{17}$ a sKB depende do acometimento de redes neurais centradas na amigdala temporal.

Hoehn-Saric e col. ${ }^{12}$ foram os primeiros a atentar para a ocorrência de desinteresse, reversivel, em 5 pacientes com diagnósticos variados em uso de fluoxetina ou fluvoxamina. A certa altura do tratamento, começaram a negligenciar obrigações familiares e profissionais, deixando de pagar aluguel, faltando ao serviço ou desprezando os filhos, para passar a maior parte do tempo ociosos diante da televisão. Hoehn-Saric e col. " estudaram o caso de um rapaz de 23 anos de idade, cujos sintomasalvo de obsessão-compulsão responderam a $100 \mathrm{mg}$ diários de fluoxetina, tornando-se, ao mesmo tempo, indiferente, desatento e esquecido e cometendo erros frequentes no trabalho. A neuropsicologia e a tomografia de emissão de fóton único (SPECT) revelaram padrão bifrontal que desapareceu, com os efeitos colaterais, após suspensão da droga. George e Trimble ${ }^{9}$ relataram um paciente com sindrome de Tourette e distúrbio obsessivo-compulsivo que respondeu à fluoxetina, mas desenvolveu apatia quando a dose diária foi aumentada para $150 \mathrm{mg}$. Com a redução para $100 \mathrm{mg}$, a indiferença desapareceu, sem prejuízo dos efeitos terapêuticos. Todos eram indivíduos competentes e responsáveis e as alteraçóes comportamentais causaram estranheza em quem os conhecia. Nenhum apresentou sonolência, fadiga ou confusão mental. A ocorrência de "indiferença" no curso do tratamento antidepressivo de pacientes, levou-nos a rever a conceituação clínica da apatia e considerar alguns dos possiveis mecanismos cerebrais em jogo. Observações desse tipo deverão aumentar, dado o emprego crescente dos inibidores seletivos de recaptação de serotonina (ISRSs) e dos inibidores reversíveis da monoamino-oxidase (IMAOs).

\section{RELATO DOS CASOS}

Caso 1 - Uma professora primária, 26 anos de idade, veio à consulta por "depressão e crises de hostilidade". Desde adolescente, suscetivel a periodos de "complexo de inferioridade", que aumentaram em duração e passaram a se acompanhar de acessos de descontrole físico e verbal, nos quais esbravejava e quebrava pecas da mobilia sem incitaçăo visivel. Os acessos duravam meia hora e terminavam em pranto e sono. Despertava arrependida, com recordação nebulosa do ocorrido. Por causa deles, procurou auxilio psiquiátrico dois anos antes, mas abandonou o tratamento por sonolência excessiva. Continuou piorando, com acréscimo de sintomas de linhagem depressiva, como tristeza e choro fácil, ansiedade, medos injustificados, retraimento social e baixa da atividade, necessitando de esforço anormal para levar as obrigaçðes de trabalho a bom termo. Memória c capacidade de concentração deficientes. Dois meses antes da consulta, começou a negligenciar os compromissos adiáveis. Tia e avó paternas "deprimidas", pai alcob́latra. Ao exame, orientada, chorosa e abatida, aparência descuidada; operaçöes cognitivas, nervos cranianos, força segmentar, marcha, reflexos e coordenação normais. Melhorou rapidamente com $20 \mathrm{mg} /$ dia de fluoxetina, melhora esta que prosseguiu a passo mais lento pelos dois meses subsequentes. Segundo seu esposo, aproximava-se do normal no final de novembro, quando voltou a ficar triste, ansiosa e sonolenta. Com o aumento da fluoxetina para $40 \mathrm{mg} / \mathrm{dia}$, retomou a melhora. No inicio de fevereiro de 1994, sentiu-se novamente deprimida, mas recuperou-se com o aumento da dose para $60 \mathrm{mg}$ (Figura). Exames laboratoriais essenciais e RNM do crânio normais.

Menos de um mês depois do último aumento de dose, começou a se sentir "esquisita, sem emoção, ria por rir". Associaram-se ansiedade, suor frio nas mãos, abalos musculares segmentares e generalizados e alteração peculiar do sono ("dormindo, parecia continuar acordada o tempo todo"). Em momento algum apresentou comprometimento cognitivo, agitação psicomotora, psicose ou desinibição comportamental. $O$ aspecto mais saliente desse estado - que reportava como distinto da depressão -, referia-se à ausência de experiência emocional: não se sentia alegre nem triste. Em encontros sociais, passava parte do tempo quieta, a ponto de os amigos mais chegados indagarem por que "andava tåo apática". Em outros momentos, fingia interesse pela conversa e encenava as emoçðes apropriadas de maneira mecânica: se o ambiente era alegre, ria, sorria e expressava emoçð̃es que, de fato, não sentia. Incomodava-se com a própria ausência de emoçðes: perguntava-se por que, afinal, não ria nem se sentia triste "de verdade". A indiferença emocional invadiu suas relaçðes interpessoais, incluindo amigos e marido, acompanhando-se de redução da iniciativa verbal, comportamental e sexual (libido e orgasmo). Durante o mesmo periodo, por outro lado, raciocinava com clareza, dando conta de compromissos e problemas cotidianos. Por exemplo, em certa ocasiăo, viu-se em situação que demandava tomada de decisão de longo-alcance. Tencionava pedir demissão da escola em que trabalhava no meio do ano. Informada que a direção havia 


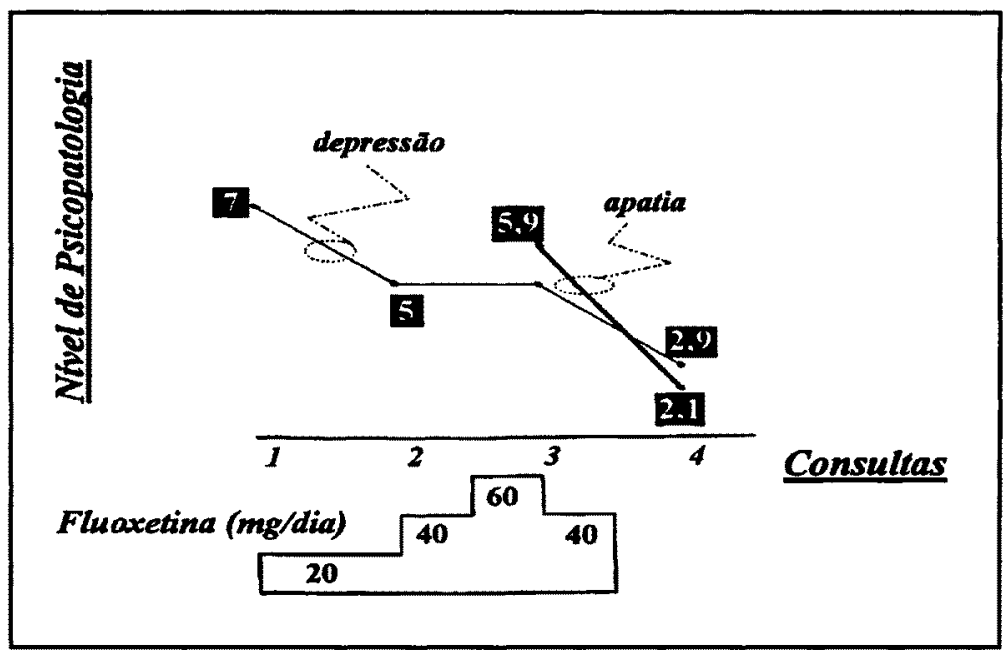

Fig. Representação gráfica da variação do nivel de psicopatologia com a dose de fluoxetina (Paciente 1). No eixo das ordenadas, valores (decimais) de depressão (escala de Hamilton modificada e apatia ${ }^{3}$. Nas abscissas, o tempo, representado pelas consultas correspondentes.

programado demissð̃es para antes, adiantou-se e desligou-se do emprego em maio, "no lugar de alguém mais necessitado, já que sairia mesmo em julho...". A decisão năo foi fácil, nao só porque contrariava seu cronograma pessoal, como - mais importante - teria que enfrentar alguns meses sem ocupação fixa, o que a assustava pela possibilidade de ficar ociosa e deprimida.

A apatia durou dois meses, durante os quais năo deu noticias. Neste período, um parente casualmente reportou-lhe sintomas identicos durante tratamento com fluoxetina. Comunicou-nos o fato e suspendemos a medicação a título de prova diagnóstica. Em duas semanas melhorou sensivelmente, com retorno da experiência emocional: falava alto e fluente, modulando bem a mímica, a voz e a gesticulação, mas, uma semana depois, seu humor decaiu drasticamente. Compareceu à consulta desanimada e sem esperança, chorando com facilidade. Novamente, distinguia esta experiência da apatia do mês anterior. Medicada com $20 \mathrm{mg} /$ dia de paroxetina, saiu da depressão em uma semana. Desde então, tem atravessado períodos quinzenais de dois dias de tristeza, desânimo e moderada incapacitação funcional. Com 6 meses de medicação regular sentia-se suficientemente bem para voltar à faculdade e conceber o primeiro filho.

Caso 2 - Um estudante de medicina, 20 anos de idade, viu-se forçado a interromper o curso no segundo ano por estado de depressăo grave, refratária aos fármacos disponíveis, respondendo, apenas, à eletroconvulsoterapia. Com a introdução progressiva da sertralina no esquema terapêtico, observou "uma sensação esquisita, de resfriamento dos sentimentos" e retenção urinária, quando a dose diária atingiu $200 \mathrm{mg}$. Introspectivamente, distinguia a apatia do desânimo e da ideação niilista da depressão: filho único, espantou-se como, "de uma hora para outra, perdera o amor pelos pais, uma das poucas coisas que ainda valiam a pena...". Com o retorno da dose pafa $150 \mathrm{mg} / \mathrm{dia}$, a apatia remitiu em menos de dois dias, com desaparecimento da dificuldade urinária e retorno da desesperança e da tristeza, próprios do estado psicopatológico anterior. Poucas semanas depois, para maximizar o beneficio da nova droga, aumentamos a dose diária de sertralina para $175 \mathrm{mg}$. Em três dias, queixou-se de indiferença "à maioria dos eventos que o cercavam, exceto aos pais", porém sem os acompanhantes vegetativos. Năo imaginou que os $25 \mathrm{mg}$ adicionais de sertralina pudessem estar ligados ao sintoma. Reduzida a dose para $150 \mathrm{mg} /$ dia, reverteu à depressão anterior. Em nenhum momento apresentou distúrbios cognitivos.

Caso 3 - Um engenheiro de 50 anos de idade, bem sucedido na profissão, veio à consulta, em outubro de 1994, após longo periodo de infortúnios pessoais e convalescença de cirurgia de hémia-de-disco, com queixa de dor no local da intervenção, fadiga, cansaço e impaciência. Ativo e empreendedor, via-se sem perspectiva e 
assustado com a possibilidade de não se recuperar da cirurgia. Pela primeira vez na vida adiava compromissos de segunda importância. Irritava-se pelas menores coisas, principalmente em casa, com os filhos; na rua, continhase para não discutir por coisas antes triviais. O sono andava leve e interrompido. Ao longo da vida, atravessou alguns periodos de "stress", que o levaram ao médico. Depressão e suicídio em parentes de primeiro grau. Confrontado com o diagnóstico de depressåo, negou-o, recusou tratamento e entrou em férias. Retornou um mês depois, pior, com queixas somáticas múltiplas, sono pouco restaurador, "baixo astral pela manhä", choro ocasional, irritação, desânimo e ansiedade crescentes. Aceitou tratamento e foi medicado com $300 \mathrm{mg} /$ dia de moclobemida e $10 \mathrm{mg}$ de clobazam à noite, com normalização gradual do sono e desaparecimento da irritação, do desânimo e da ansiedade. Em fevereiro, observou estar "apático, sem emoçōes, ligando pouco para as coisas". Conseguia raciocinar tão bem como antes, mas não operacionalizava as idéias. Por exemplo, na manhă do dia da consulta, tivera uma "intuição genial" sobre aplicação na Bolsa, mas nđo moveu um dedo para pô-la em prática. Admirou-se, depois, por nåo se importar em deixar de ganhar "uma quantia razoável". Os problemas dos filhos já não o incomodavam tanto, deixou de supervisioná-los. Largou o computador de lado, "uma de suas paixð̃es". Manteve normal o funcionamento cognitivo por todo o período. Notou retardo no orgasmo/ejaculaçăo, com redução discreta da potência erétil. Retirada a moclobemida, a reatividade emocional começou a voltar em três dias, com recuperação e antecipação do orgasmo/ejaculação para o tempo normal em duas semanas. Aos poucos, voltou a ficar irritadiço e ansioso. Medicado com $50 \mathrm{mg} /$ dia de sertralina, em poucos dias apresentou estabilização do humor, sem efeitos colaterais, exceto por discreto atraso na ejaculação. Quatro meses depois, continuava bem e produtivo, sem atenuação da resposta terapêutica.

O Caso 4 diz respeito a uma odontologista de 44 anos com diagnóstico de distimia'. Sua boa resposta à moclobemida ( $750 \mathrm{mg} /$ dia) atenuou-se após vários meses de uso. Substituidos $50 \mathrm{mg} / \mathrm{dia}$ de sertralina, em menos de dois dias desenvolveu quadro idêntico ao dos pacientes acima, que reverteu com a retirada imediata da droga.

O Paciente 5, com 54 anos e sequela de afeção cerebrovascular hemorrágica da regiåo basonuclear do hemisfério esquerdo, apresentou-se com depressão major grave' e história pessoal e familiar de múltiplos episódios de doença do humor. Tratado com amitriptilina, desenvolveu apatia acentuada ("vou à igreja como sempre, mas minha fé me abandonou...") e distúrbio cognitivo leve (latência aumentada para dizer a data e o dia da semana) quando a dose diária chegou a $150 \mathrm{mg}$. Novamente, com base na experiência dos três primeiros pacientes e cientes do perfil cognitivo-anticolinérgico inerente aos tricíclicos, retiramos a droga, verificando retorno ao estado pré-jatrogênico em menos de uma semana.

\section{DISCUSSÃO}

\section{Apatia como manifestação psicopatológica independente}

Esses casos destacam um sintoma psicopatológico peculiar caracterizado pela abolição (ou redução) da capacidade de experimentar emoções. A condição - a que denominamos "apatia", para diferenciá-la da abulia e da avolição com os quais é comumente confundida - guardou estreita relação temporal com as variações das doses dos antidepressivos (por vezes tão pequenas quanto $15 \%$, Caso 2), deixando poucas dúvidas quanto à participação dessas substâncias na gênese da apatia, podendo ter resultado de sua afinidade por receptores serotoninérgicos centrais ${ }^{16}$. Essa idéia foi reforçada pela concomitância de sintomas disautonômicos serotoninérgicos encontrados em quase todos (distúrbio do sono e da regulação sexual). Não obstante, quaisquer que sejam os mecanismos envolvidos, os efeitos antidepressivo e "apatogênico" são dissociáveis e, até certo ponto, independentes ${ }^{9,11,12}$. Nossos pacientes e os indicados na Introdução, sugerem a possibilidade da apatia quimicamente induzida como categoria etiológica específica, seja pela (i) disfunção neuroquímica inerente ao processo patológico de base (lesões do lobo temporal anterior, por exemplo ${ }^{13}$ ), seja por (ii) iatrogenia, como em nossos casos. Infelizmente, o pouco material publicado não deixa claro se as alterações comportamentais se deveram à apatia, à avolição $o^{1}$ ou à abulia ${ }^{\mathrm{k}}$, pois, com frequência, o termo "apatia" é utilizado para designar sintomas avolitivos ou abúlicos ${ }^{7,12,14,19,21,23}$. Dado nosso interesse pela questão, esse aspecto foi sistematicamente considerado nos pacientes, permitindo-nos afiançar a natureza apática verdadeira das queixas. Por exemplo, a paciente da série não abandonou sua rotina e conseguia, mesmo, organizar comportamentos de conteúdo altruísta, como no caso de sua demissão voluntária. Em outras palavras, não desenvolveu avolição ou abulia em graus 
comparáveis. Sua condição, como nos outros dois casos, foi assinalada por estado peculiar no qual objetos, pessoas e eventos de relevância pessoal foram despojados de seus respectivos atributos emocionais e vivenciados como neutros (ou próximo a isso): marido, amigos ou qualquer item comum da mobília deixaram de se distinguir em termos de significado pessoal - haviam-se tornado afetivamente nivelados.

\section{Apatia Multimodal}

Indicios de que a experiência emocional nos primatas se organiza sobre bases supramodais foram originalmente sugeridos em experimento clássico de dois tempos cirúrgicos ${ }^{6}$, em que se destruíam a amigdala ou o pólo temporal de um lado. Este procedimento inicial não modificava a natureza emocional dos animais, naturalmente selvagens e intratáveis. Em seguida, para restringir as aferências visuais de cada nervo óptico ao hemisfério ipsilateral, seccionavam-se as comissuras cerebrais e o quiasma óptico. Depois de operados, quando viam o mundo pelo olho ligado ao hemisfério intacto, os animais continuavam reagindo ao ambiente como antes. Todavia, quando os mesmos estímulos incidiam sobre o olho conectado ao hemisfério lesado, mostravam-se paradoxalmente indiferentes. A mansidão se restringia aos estímulos visuais, uma vez que, por exemplo, contatos inesperados com o braço deflagravam ataques imediatos. Produziu-se, desta forma, uma variante modalidade-específica (visual) de placidez. Evidências clínico-anatômicas apontam para a existência de fenômeno comparável no homem. Bauer ${ }^{2}$ estudou um paciente de 39 anos, cujas respostas emocionais a estímulos visuais cotidianos foram abolidas por hematomas lobares occípitotemporais bilaterais, aproximadamente simétricos. As lesões alojaram-se na face inferomedial dos hemisférios, em posição ideal para interromper projeções visuais complexas para estruturas límbicas anterobasais ${ }^{24}$, justificando a caprichosa desconexão visuoafetiva clinicamente observada. $\mathrm{Na}$ esfera auditiva, Heilman e col. ${ }^{10}$ documentaram a abolição seletiva da compreensão dos aspectos emocionais da fala ouvida. Essas observações indicam que, para que os eventos ambientais ressonem afetivamente de maneira apropriada, as regiões sensitivo-sensoriais hemisféricas devem estar normalmente conectadas às regiðes amigdala $\leftrightarrow$ têmporo-polares, decisivas para o processamento multimodal da experiência emocional ${ }^{22}$.

Nos nossos pacientes, a fluoxetina, a sertralina, a moclobemida e a amitriptilina parecem ter promovido algum tipo de "dissecção química" da apatia, indicando que os antidepressivos detêm alguma açđo seletiva sobre a integração da experiência emocional às idéias e percepções de diversas modalidades sensoriais. Assim, o envolvimento de circuitos ligados à cartografia emocional do ambiente pode se traduzir pelo comprometimento da experiência emocional em mais de uma modalidade sensorial, como nos nossos casos (apatia multimodal), ou em apenas uma modalidade (apatia unimodal), conforme demonstram a hipoemotividade visual ${ }^{2}$ e a agnosia afetiva auditiva ${ }^{10}$.

A hipótese acima considera que a região estratégica para a produção de apatia multimodal por lesð̃es cerebrais focais se encontre na amígdala ou em suas imediações, interrompendo conexðes com o córtex têmporo-polar, ponto rostral de convergência de reprojeçðes neocórtico-limbicas bidirecionais ${ }^{18.23}$. Como os circuitos amígdala $\leftrightarrow$ têmporo-polares estabelecem conexðes recíprocas com as principais redes associativas neocorticais posteriores e pré-frontais, acreditamos ser esta região estratégica para a integração da percepção multimodal do ambiente ou de imagens mentais com os respectivos tons e qualidades emocionais e seus marcadores somáticos ${ }^{5,15}$. A interpretação que oferecemos para os nossos casos, portanto, difere um pouco da dos autores que atribuíram a "indiferença" pelos ISRSs ao comprometimento de circuitos frontais", Como aqueles pacientes manifestaram síndromes mais complexas e a apatia não parece ter sido sistematicamente diferenciada da avolição e da abulia, acreditamos que os nossos casos e os deles não são superponiveis. De um modo ou outro, a ausência de hipermetamorfose, tendência oral, desinibição e avolição em graus proporcionais aos da indiferença emocional confere individualidade à apatia e sugere que os sintomas tradicionalmente enfeixados na sKB podem ser individualmente reproduzidos pela manipulação farmacológica de circuitos neuroquímicos especializados ${ }^{4}$. 


\section{REFERÊNCIAS}

1. Andreasen NC, Black DW. Introductory textbook of psychiatry, Ed2. Washington DC: American Psychiatric Press, 1995.

2. Bauer RM. Visual hypoemotionality as a symptom of visual-limbic disconnection in man. Arch Neurol, 1982;39:702-708.

3. Bech $P$, Kastrup M, Rafaelsen OJ. Mini-compendium of rating scales for states of anxiety, depression, mania, schizophrenia with corresponding DSM-III syndromes. Acta Psychiat Scand 1986;73(Suppl 326):1-37.

4. Costello CG. Research on symptoms versus research on syndromes: arguments in favour of allocating more research time to the study of symptoms. Br J Psychiatry 1992;160:304-308.

5. Damasio AR. Descartes' error. emotion, reason, and the human brain. New York: Avon Books, 1994.

6. Downer JDC. Changes in visual gnostic function and emotional behavior following unilateral temporal damage in the "splitbrain" monkey. Nature 1961;191:50-51.

7. Fedoroff JP, Starkstein SE, Price T, Leiguarda R. Apathy following cerebrovascular lesions. Neurology 1994;44(Suppl 2):A376.

8. Fisher CM. Abulia minor vs agitated behavior. Clin Neurosurg 1984;31:9-31.

9. George MS, Trimble MR. A fluvoxamine-induced frontal lobe syndrome in a patient with comorbid Gilles de la Tourette's syndrome and obsessive compulsive disorder (letter). J Clin Psychiatry 1992;53:379.

10. Heilman KM, Scholes R, Watson RT. Auditory affective agnosia: disturbed comprehension of affective speech. J Neurol Neurosurg Psychiatry 1975;38:69-72.

11. Hoehn-Saric R, Harris GJ, Pearlson GD, Cox CS, Machlin SR, Camargo EE. A fluoxetine-induced frontal lobe syndrome in an obsessive compulsive patient. J Clin Psychiatry 1991;52:131-133.

12. Hoehn-Saric R, Lipsey JR, McLeod DR. Apathy and indifference in patients on fluvoxamine and fluoxetine. $J$ Clin Psychopharmacol 1990;10:343-345.

13. Lilly R, Cummings JL, Benson DF, Frankel M. The human Klaver-Bucy syndrome. Neurology 1983;33:1141-1145.

14. Marin RS. Differential diagnosis and classification of apathy. Am J Psychiatry 1990;147:22-30.

15. Mesulam M-M, Perry J. The diagnosis of love-sickness: experimental psychophysiology without the polygraph. Psychophysiology 1972;9:546-551.

16. Murphy DL. Neuropsychiatric disorders and the multiple human brain serotonin receptor subtypes and subsystems. Neuropsychopharmacology 1990;3:457-471.

17. Murray EA, Mishkin M. Amygdalectomy impairs crossmodal associations in monkeys. Science 1985;228:604-606.

18. Pandya DN, Yeterian EH. Hodology of limbic and related structures: cortical and commissural connections. In: Wieser HG, Elger CE (eds). Presurgical evaluation of epileptics. Berlin: Springer-Verlag, 1987:3-14.

19. Poeck K. The Klüver-Bucy syndrome in man. In Vinken PJ, Bruyn GW (eds). Handbook of clinical neurology, Vol. 1 (45) \{Fredericks JAM (ed) Clinical neuropsychology]. Amsterdam: Elsevier, 1985:257-263.

20. Ross ED, Rush AJ. Diagnosis and neuroanatomical correlates of depression in brain-damaged patients: implications for a neurology of depression. Arch Gen Psychiatry, 1981;38:1344-1354.

21. Starkstein SE, Mayberg HS, Preziosi TJ, Andrezejewski P, Leiguarda R, Robinson RG. Reliability, validity, and clinical correlates of apathy in Parkinson's disease. J Neuropsychiatry Clin Neurosci 1992;4:47-50.

22. Tranel D, Hyman BT. Neuropsychological correlates of bilateral amygdala damage. Arch Neurol 1990;47:349-355.

23. Turner BH, Mishkin M, Knapp M. Organization of the amygdalopetal projections from modality-specific cortical association areas in the monkey. J Comp Neurol 1980;191:515-543.

24. Tusa RJ, Ungerleider LG. The inferior longitudinal fasciculus: a reexamination in humans and monkeys. Ann Neurol 1985;18:583-591.

25. Zilbovicius M, Rancurel G, Samson Y, Leder S, Bruck B, Raynaud C. Apathy and disinhibition are related to different patterns of frontal hypoperfusion in Pick's disease. Neurology 1992;42(Suppl 3): 347. 